\title{
Air and Sound Pollution Monitoring System using Cloud Computing
}

\author{
D. Ganeshkumar, V. Parimala, S. Santhoshkumar, T. Vignesh, M. Surendar \\ P. A. College of Engineering and Technology
}

\begin{abstract}
An IoT based technique to screen the Air Quality and the Noise Intensity in a specified area, has been proposed. The obligatory advances must be embraced to control and suitably screen this circumstance. Internet of Things permits a data can be traded over Internet to and from a gadget as variable or parameter. This system suits for environment monitoring as its technology influencing greater. To structure an IoT based sound and air pollution observation, a framework is designated with the assistance of $\mathrm{Wi}-\mathrm{Fi}$ and data access is configured with cloud for the periodical storage and access.
\end{abstract}

Keywords : Pollution Monitoring, IoT, Cloud Computing

\section{INTRODUCTION}

Air and sound pollution is an increasing problem these days. It is important to screen the air and sound contamination levels to guarantee a solid and safe condition of environment. The environmental problems like the expansion in modern plants and framework have affected the prerequisite of keen checking framework. In recent times, it is simpler to shape correspondence among people and gadgets. Since Internet of Things has high effectiveness because of its simplicity.

Sensors and interface modules are associated with the web to make the estimating procedure exact and easier than moving to the various locations to collect the data after analyzing. This lengthy process is replaced by this proposed work. It is more tough move to dissect the natural factors and making a stage for the issue if it is done rapidly. In this model a Raspberry pi 3B controller, Gas sensor, Sound sensor, Temperature sensor are used for monitoring and interface.

Air and sound contamination is an expanding issue nowadays. It is essential to screen the air and sound pollution levels to ensure a strong and safe state of condition in the environment. The natural issues like the extension in present day plants and structure have influenced the essential of finite and micro level analyzing system.

\section{LITERATURE SURVEY}

Various research carried out in this area shows the systems and interfaces are continuously developed to adopt required performance in the applications.

Giovanni B. Fioccola et al. have proposed, Arduino based air pollution monitor system[1]. Air contamination is hazard factor for numerous wellbeing conditions including skin and eye disease, disturbance of nose, throat and eyes. It likewise causes genuine conditions like coronary illness, lung malignant growth trouble in breathing and many. At that point put away to cloud stage that keeps up the information accepting from the detecting modules. The idea of observing utilizing a microcontroller which gauges the air signals. Gas sensors are utilized to quantify the contamination level. This information is transferred by means of web and can likewise be checked in cell phones.

In paper[2] Arushi Singh et al. have proposed a system which uses sound and air sensors to detect the information continually and afterward transmit the information. The principle goal of undertaking is by utilizing different sensors, GSM/GPRS module and Cloud/server to structure a productive and remote framework to observing the degree of different poisons causing contamination and to limit the impact of these parameters without influencing the common habitat and give live updates to keep away from clashes. A raspberry pi module intervenes with the sensors and procedures the information. The Distributed computing is an efficient answer for the overseeing of sensor information. This paper presents Polluino, a framework for observing the air contamination through Arduino. Also, a Cloud-based stage that oversees information originating from air quality sensors is created.

In paper[3] L.Ezhilarasi et al. have proposed a using a Zigbee wireless sensor network to detect the various parameters in the surroundings. The mechanical air contamination checking framework dependent on the innovation of remote sensor systems (WSNs). This framework is incorporated with the worldwide framework for portable interchanges (GSM).And its correspondence convention utilized is zigbee. The framework comprises of sensor hubs, a control community and information base through which detecting information can be put away for history and tentative arrangements.

In paper[4] Mahantesh B Dalawai et al. have used a GSM module and a web server to monitor the pollution levels. In the parameters of the smoke sensor and noise sensor will upload the data to the cloud storage at every time. Pollutants can cause damages in human health and other living organisms. The available pollutant emission monitoring systems, such as Opsis, Codel, Urac and TAS-Air metrics are typically expensive. The proposed system which uses sound and air sensors to detect the information continually and afterward transmit the information. . Parking management is also main public issue in most of metropolitan cities and that is also the reason of many problems. In addition, these systems have limitations to be installed on chimney due to their principle of operation.

In paper[5] Dr. A Sumithra et al. have proposed Smart cities is based on the Technology and communication. Various 
modules have also been used to monitor the various environmental problems. This framework utilizes air and sound sensors to screen the information and afterward transfer it to cloud server in type of advanced information. The Distributed computing is an efficient answer for the overseeing of sensor information. This paper presents Polluino, a framework for observing the air contamination through Arduino. In addition, a Cloud-based stage that oversees information originating from air quality sensors is created.

In paper[6] SRM. ArthiShri et al. have proposed the concept of monitoring using a microcontroller which measures the atmosphere signals. Gas sensors are used to measure the pollution level. This data is uploaded via internet and can also be verified in mobile phones. . Internet of Things is nowadays finding profound use in each and every sector, plays a key role in our air quality monitoring system too. an industrial air pollution monitoring system based on the technology of wireless sensor networks WSNs. This system is integrated with the global system for mobile communications GSM and its communication protocol used is zigbee. Internet of Things converging with cloud computing offers a novel technique for better management of data coming from different sensors, collected and transmitted by low power, low cost ARM based minicomputer Raspberry pi.

\section{PROPOSED METHODOLOGY}

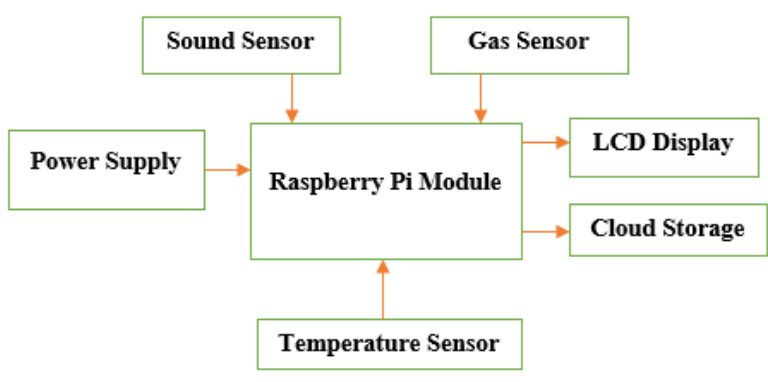

Fig. 1. Block Diagram of Proposed System

\section{A. Air Quality Index and Health Impacts}

As AQI expands, potential outcomes of different wellbeing dangers are additionally increments. AQI can be broke down by computing normal toxin fixation over period.

$\mathrm{I}=\left[\mathrm{I}_{\text {high }}-\mathrm{I}_{\text {low }} / \mathrm{C}_{\text {high }}-\mathrm{C}_{\text {low }}\right]\left(\mathrm{C}-\mathrm{C}_{\text {low }}\right)+\mathrm{I}_{\text {low }}$

where

I = Air Quality Index (AQI)

$\mathrm{C}=$ Concentration of the pollutant

$\mathrm{C}_{\text {low }}=$ Breaking point of concentration lesser than $\mathrm{C}$

$\mathrm{C}_{\text {high }}=$ Breaking point of concentration greater than $\mathrm{C}$

$\mathrm{I}_{\text {low }}=$ Breakpoint of index corresponding to $\mathrm{C}_{\text {low. }}$.

$\mathrm{I}_{\text {high }}=$ Breakpoint of index corresponding to $\mathrm{C}_{\text {high }}$.
The Health Impacts as regulated by the authority are given below:

TABLE 1. AIR QUALITY INDEX AND THEIR HEALTH IMPACTS

\begin{tabular}{|l|l|l|}
\hline $\begin{array}{l}\text { Range } \\
\text { In ppm }\end{array}$ & Air Quality Index & Health Impacts \\
\hline $0-50$ & Normal impact & Less effects. \\
\hline $51-100$ & Satisfactory & Low Breathing Distress. \\
\hline $101-200$ & Moderate Impact & $\begin{array}{l}\text { Breathing discomfort and } \\
\text { Soreness to people }\end{array}$ \\
\hline $201-300$ & High Impact & $\begin{array}{l}\text { Breathing disturbs and } \\
\text { cause great impact. }\end{array}$ \\
\hline $301-400$ & Great Impact & $\begin{array}{l}\text { Cause respiratory } \\
\text { sickness. }\end{array}$ \\
\hline $401-500$ & Serious Impact & $\begin{array}{l}\text { Severe respiratory lungs } \\
\text { problems. }\end{array}$ \\
\hline
\end{tabular}

\section{B. Noise Pollution Analysis}

Noise pollution has the most damaging effect on Living life forms. It for the most part happens because of the sound originating from vehicles, ventures, mechanical work, apparatus, and so forth. The noise gauges are managed by the government for the wellbeing measurement. Clamor contamination prompts numerous interminable and socially noteworthy effects. it is increasingly imperative to distinguish the wellsprings of high noise levels and control them. In most of the parts, it happens in light of the sound starting from vehicles, adventures, mechanical work, device, etc. The disturbance measures are overseen by the lawmaking body.

TABLE 2. STANDARD NOISE LEVEL LIMIT IN DIFFERENT AREA

\begin{tabular}{|l|c|c|}
\hline \multicolumn{1}{|c|}{ Area } & Day & Night \\
\hline Industrial & 75 & 70 \\
\hline Commercial & 65 & 55 \\
\hline Residential & 55 & 45 \\
\hline Silenced & 50 & 40 \\
\hline
\end{tabular}

In this paper the noise pollution is calculated based on the vibrations and their Intensity. Similarly the value 40 is the normalized limit, below which the no sensor will detects the sound intensity.

\section{Temperature and Humidity Analysis}

Temperature rising is a serious issue and cause more prominent effect on earth inside 10 years. It happens commonly because of a dangerous atmospheric deviation. The extra subject of our task is to guarantee the security furthest reaches of temperature in condition. The safe place of natural temperature is endorsed between 16 to 27 degree celcius. At the point when you consider that individuals for the most part are most agreeable when the relative stickiness is around 40 percent, it can be perceived how to dry indoor air that would cause adverse effects. Low stickiness causes friction based electricity, dry skin, lips and hair, scratchy throats and noses, and tingling and drying. 
Proposed model which consists of following modules, namely,

1) Air Quality Index Module

2) Sound Intensity Detection Module

3) Temperature Humidity Detection Module

4) Cloud Module

5) Notification Module.

The data are acquired from sensors which are sent to Raspberry pi. The calculation of Air quality and Sound intensity are analyzed. Those data are uploaded to cloud along with the temperature value. This data can also be viewed in LCD display. If the pollution exceeds the threshold then a notification will be sent to Email. And those data are displayed in cloud data sheet.

\section{1) Air Quality Index Module}

Air Quality List is estimated relying upon toxins, for example,Carbon monoxide, Sulfur Dioxide and nitrogen dioxide and estimated by MQ - 135 sensor. It proficiently recognizes the parameters level in air. This sensor is picked for its broad recognizing extension, quick reaction, dependability. Comprehension and checking air quality is fundamental to air researchers to help lessen emanations, ensure human wellbeing and nature. Air Quality Index is evaluated depending upon depending upon toxic elements present in the air like Carbon monoxide, Sulphur Dioxide. It capably perceives the parameters level in air by relevant sensors. Figure 2 shows the Air Quality index at a fixed Position.

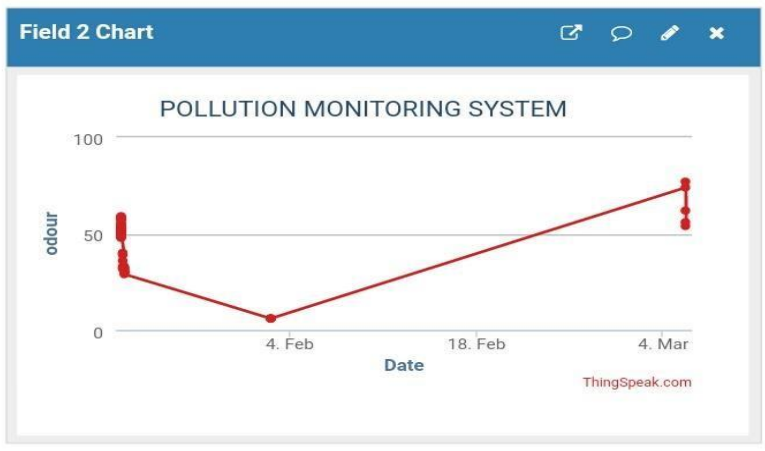

Fig. 2. Air Quality index at a fixed Position

\section{2) Sound Intensity Detection Module}

Sound Sensor is used to evaluate sound force to screen Sound Contamination in a specific zone. Right when sensor recognizes sound, it frames the yield signal which is sent to Raspberry $\mathrm{Pi}$ and it again plays out the crucial introduction for last suitable examination. A decibel meter is an estimating instrument used to evaluate commotion or sound levels by estimating sound weight. A sound level meter utilizes a mouthpiece to catch sound. Figure 3 shows the Sound Intensity Detection at a fixed Position

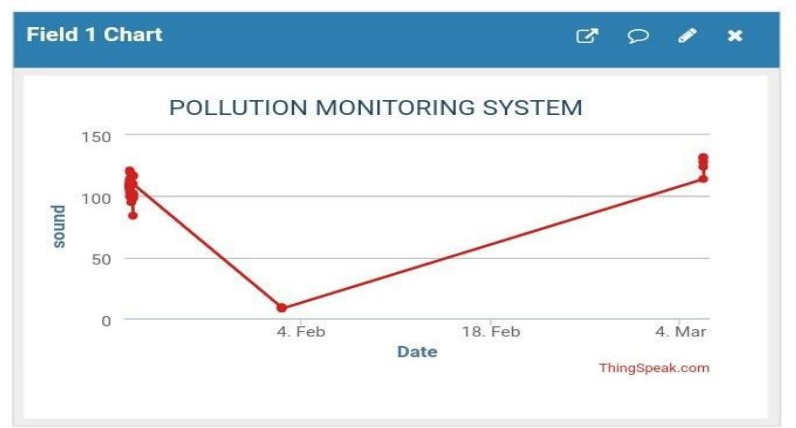

Fig. 3. Sound Intensity Detection at a fixed Position

\section{3) Temperature and Humidity Detection Module}

Temperature and Moistness Sensor is utilized to quantify Temperature and mugginess in a particular region. It identifies the temperature levels and procedures the yield and sent it to the Raspberry Pi are in computerized values. This module incorporates DHT11 sensor and other required parts on a little PCB. The DHT11 sensor incorporates a resistivetype stickiness estimation part, and gives adjusted advanced sign yield. It has high dependability and great long haul solidness, on account of the select computerized signal obtaining strategy and temperature and moistness detecting innovation. This module consolidates DHT11 sensor and other required parts on a little PCB. The DHT11 sensor fuses a resistive type tenacity estimation section as shown in Figure 4 and Figure 5.

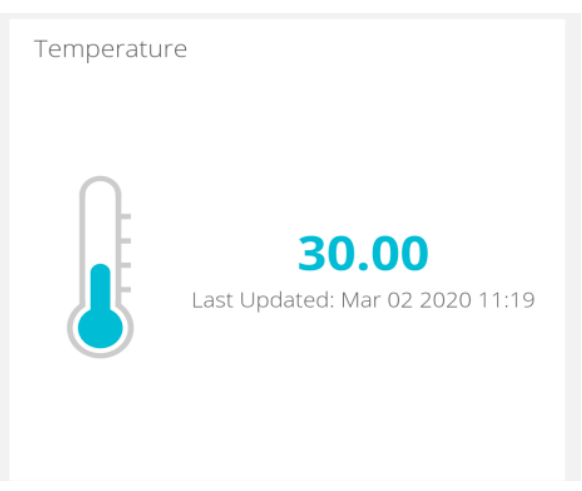

Fig. 4. Temperature Detection at a fixed Position

\section{Humidity}

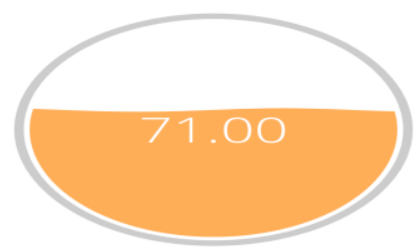

Fig. 5. Humidity Detection at a fixed Position 


\section{4) Cloud Module}

Web access to meld Cloud system is required and it was designated by Wi-Fi module present in the Raspberry Pi. With the help of this interface the acquired data are transferred electronically to a Distributed storage. Those saved snippets of data can be investigated for testing and also explored over a period for verification. The cloud is essentially an assortment of servers housed in gigantic, section of land filling buildings and possessed by a portion of the world's biggest enterprises. This basically implies information sites on PCs like Microsoft, Amazon and Apple to merge with Cloud framework. Wi-Fi module present in the Raspberry Pi associates the data electronically for Distributed stockpiling.

\section{5) Notification Module}

In the Raspberry $\mathrm{Pi}$, use control enunciations are incorporated for the irregularity notice. If any of the parameters outperforms the breaking point extent of its value, imperative advances are taken to send an Email. In the control enunciation it is basic to give the most ideal email address which is tended for information whenever some irregularity occurs. Notice is sent by the system and can be utilized for remote actuation at home for emergency. This module is perfect for flagging interruption, assault, fire, gas spillage or other specialized imperfections. The unit can work autonomously with alert control board.

\section{RESULT AND DISCUSSION}

This paper discusses the methodology and results of each of design for the concerned data. All methods used in this paper provides accurate results in classification with high accuracy and widely used cloud storages. Its process are done in inner network so its saves time, reduces the labour work and result is also high. This method is very useful for all consumers.

\section{CONCLUSION}

A smart way to monitor the environmental parameters using Raspberry Pi module has been discussed in this paper. This concept of IoT helps to develop the quality of air, monitor the noise level and temperature. And also it is a lowcost and efficient method. The monitoring of accumulated data in the cloud storage helps to determine the numerous patterns in the environment and helpful in making awareness to the public.

\section{FUTURE SCOPE}

This work can be illustrated and developed with the Artificial Intelligence for estimating ecological parameters in a productive manner and thus helpful to the environment condition monitoring on different climatic conditions.

\section{REFERENCES}

[1] L.Ezhilarasi, K.Sripriya, A.Suganya, K.Vinodhini, “ System For Monitoring Air And Sound Pollution Using Arduino Controller Technology." International Research Journal in Advanced Engineering and Technology, 2017.

[2] Mahantesh B Dalawai, Siva Yellampalli, Pradeep S.V, "IOT Based Air and Noise Pollution Monitoring in Urban and Rural Areas, Important Zones like Schools and Hospitals in Real Time." International Journal of Innovative Research In Technology, 2017
[3] Godbless Swagarya, Subi Kaijage, Ramadhani S. Sinde "Air Pollution Monitoring System based on Wireless SimulationNetwork." Innovative System Design and Engineering, 2014.

[4] Giovanni B. Fioccola , Raffaele Sommese, Imma Tufano, Roberto Canonico, Giorgio Ventre, " Polluino: An efficient cloud-based management of IoT devices." IEEE 2nd International Forum on Research and Technologies for Society and Industry Leveraging a better tomorrow, 2016.

[5] Somansh Kumar, Ashish Jasuja,“ Air quality monitoring system based on IoT using Raspberry Pi.", International Conference on Computing, Communication and Automation , 2017.

[6] Seung Ho Kim, Jong Mun Jeong, Min Tae Hwang, Chang Soon Kang, "Development of an IoT-based environment monitoring system.” International Conference on Information and Communication Technology Convergence, 2017.

[7] Kan Zheng, Shaohang Zhao, Zhe Hang, Xiong Xiong, Wei Xiang, "Design and Implementation of LPWA based Air Quality Monitoring System" IEEE international Forum, 2016.

[8] Khaled Bhashir Shaban, Abdullah Kadri, Eman Rezk, "Urban Air Pollution Monitoring SystemWith Forecasting Models" IEEE Journal based on Sensors, 2016.

[9] A. Sumithra, J.Jane Ida, K. Karthika, S. Gavaskar, "A Smart Environmental Monitoring System Using Internet Of Things." International Journal of Scientific Engineering and Applied Science, 2016.

[10] Mohannad Ibrahim, Abdelghafor Elgamri, Sharief Babiker, Ahmed Mohamed, "Internet of things based smart environmental monitoring using the Raspberry-Pi computer." 5th International Conference on Information Processing and Communications , 2015.

\section{AUTHORS PROFILE}

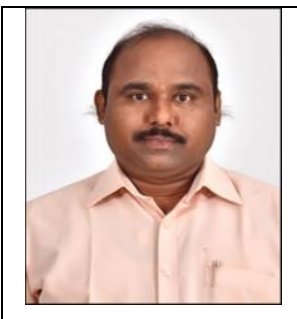

Dr.D.Ganeshkumar has completed his BE(Electronics and Instrumentation Engineering), ME(Applied Electronics) and received his Ph.D in the Faculty of Information and Communication Engineering from Anna University during 2013. Has more than 20 years of Teaching experience and presently working as Professor in P. A. College of Engineering and Technology. Published 24 papers in International \& National Journals, 22 papers in Conferences, 3 patents and 2 books. Fellow Member in IE, Senior Member in IEEE and Member in ISTE \& ISOI. Principal Investigator for DST, Govt. of India funded project and got financial assistance from various Funding Agencies like AICTE, BRNS, ISRO, CSIR, ICMR for conducting sponsored programmes. His areas of interests are Virtual Instrumentation, Process Control, Networking and Tamil Literature

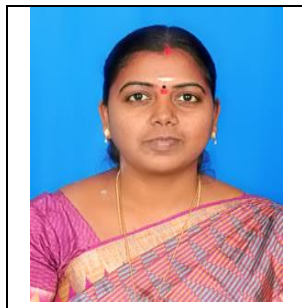

Dr.V.Parimala has completed her BE(Electrical and Electronics Engineering), ME(Power Electronics and Drives) and received her Ph.D in the Faculty of Electrical Engineering from Anna University during 2017. Has more than 18 years of Teaching experience and presently working as Professor in P. A. College of Engineering and Technology. Published 12 papers in International Journals, 20 papers in Conferences, one patent and one book. Member in ISTE, Senior Member in IEEE and approved Energy Manager in Bureau of Energy Efficiency. Her areas of interests are Power Electronics, Power Quality, Renewable Energy System and Virtual Instrumentation. 


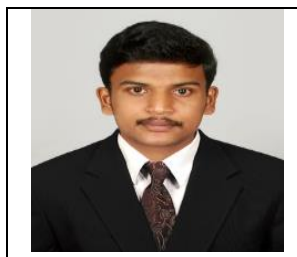

S. Santhoshkumar is pursuing his Bachelor's Degree in Electronics and Communication Engineering in P. A. College of

Engineering and Technology, Anna University. Active member in IETE Students forum and contributed to various technical activities and participated in various seminars and workshops. His areas of interests are Embedded Systems, Networking and Cloud Computing.

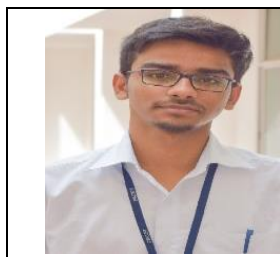

T. Vignesh is pursuing his Bachelor's Degree in Electronics and Communication Engineering in P. A. College of Engineering and Technology, Anna University. Active member in IETE Students forum and played major roles in organizing various technical events. Participated in technical activities and project contests. His areas of interests are Embedded Systems, Programming \& Simulation and Cloud Computing.

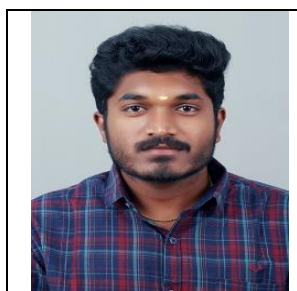

M. Surendar is pursuing his Bachelor's Degree in Electronics and Communication Engineering in P. A. College of Engineering and Technology, Anna University. Active member in IETE Students forum and organized students association activities for technical and managerial events. Participated in technical activities, seminars and workshops. His areas of interests are Electronic System Design, Communication Systems and Cloud Computing. 